\title{
Utilization of Blood and Appropriateness of Blood Transfusion in a Department of Obstetrics and Gynecology in Karachi
}

\author{
Samia Husain ${ }^{1}$, Rahila Imtiaz ${ }^{2}$, Sonia Husain ${ }^{3}$, Rubina Izhar $^{4}$
}

\begin{abstract}
Aim: To assess the utilization of blood and appropriateness of blood transfusion using utilization indices in the gynecology and obstetrics department of a tertiary care center.

Materials and methods: A retrospective observational study was carried out in Gynae unit 3 of Abbasi Shaheed Hospital from July 1, 2016, to December 31, 2016. For this study, case records of all women who had an elective or emergency procedure were compiled and reviewed. The blood utilization indices, cross-matched to the transfusion ratio $(\mathrm{C} / \mathrm{T}$ ratio $=$ number of units cross-matched/number of units transfused), transfusion probability (\%T = number of patients transfused/number of patients cross-matched $\times 100)$, and transfusion index ( $\mathrm{TI}=$ number of units transfused/number of patients cross-matched) were calculated for all.

Results: A total of 598 patients underwent major elective and emergency surgical procedures in the department. These patients were requested to prepare 1,074 units of blood. From a total of 1,074 units cross-matched, 374 were transfused. Thus, only $34.8 \%$ of the cross-matched blood was utilized. Of the 598 patients for whom blood was cross-matched, only 279 (46.65\%) patients were transfused. The overall blood transfusion indices of the requested blood, C/T ratio, $\% \mathrm{~T}$, and TI, were $2.87,46 \%$, and 0.62 .

Conclusion: Our study showed underutilization of blood in terms of cross-matched to the transfusion ratio but the probability of transfusion and the transfusion index were appropriate.

Clinical significance: Blood ordering practices need to be reviewed periodically in all units.

Keywords: Blood utilization, Maximal surgical blood ordering schedule, Transfusion.

Journal of South Asian Federation of Obstetrics and Gynaecology (2019): 10.5005/jp-journals-10006-1725
\end{abstract}

\section{INTRODUCTION}

Ordering blood is a common practice and transfusions are an important part of resuscitating and managing obstetrical emergencies. The request for blood is usually made prior to the operation and is based on the assumption of worst-case scenarios. ${ }^{1}$ This results in cross-matching of huge number of units that are left unutilized. $^{2}$

The utilization rate varies from $5 \%$ to $40 \%$ worldwide. Overordering of blood has been reported worldwide since Friedman first reported the maximal surgical blood ordering system. ${ }^{3}$ Many studies favor adoption of the maximal surgical blood order schedule for reducing overordering and improving utilization of blood. ${ }^{2,4}$ This calculation is derived from institutional usage statistics calculated by blood indices. ${ }^{3}$

Rational transfusion is a concept introduced to reinforce the fact that blood should only be transfused if necessary. ${ }^{5}$ According to current estimates, about 1.2-1.5 million units of blood are being transfused annually in Pakistan. In a developing country like Pakistan, this wastage of resources is totally uncalled for. ${ }^{6}$ Since WHO discouraged single-unit transfusions, two-unit transfusions have taken their place that has further aggravated the problem, taking a bigger bite from our meager resources. ${ }^{7}$

The blood ordering practices can be evaluated using indices that have been well described. These indicators then help formulate a maximal surgical blood ordering schedule (MSBOS). The Boral and Henry's cross-matched to transfusion ratio (C/T ratio), ${ }^{8}$ probability of a transfusion for a given procedure (denoted by $\% \mathrm{~T}$ ) proposed by Mead et al., ${ }^{9}$ and the transfusion index ( $\left.\mathrm{TI}\right)$, i.e., the average number of units used per patient cross-matched are few indicators that have been previously used..$^{10}$ \begin{tabular}{l}
\hline${ }^{1-4}$ Department of Gynecology and Obstetrics, Abbasi Shaheed \\
Hospital, Karachi, Sindh, Pakistan \\
Corresponding Author: Rahila Imtiaz, Department of Gynecology and \\
Obstetrics, Abbasi Shaheed Hospital, Karachi, Sindh, Pakistan, Phone: \\
+923332339752, e-mail: rahilaimtiaz1973@gmail.com \\
How to cite this article: Husain S, Imtiaz R, Husain S, et al. Utilization
\end{tabular} of Blood and Appropriateness of Blood Transfusion in a Department of Obstetrics and Gynecology in Karachi. J South Asian Feder Obst Gynae 2019;11(6):345-348.

Source of support: Nil

Conflict of interest: None

The implementation of the blood conserving protocol has succeeded in limiting this underutilization. ${ }^{2,4}$ The MSBOS is a blood conserving protocol that enables clinicians to ascertain the likely need of cross-matched blood prior to a surgery. Using the prior record from the cases and the blood arranged for these cases, a figure is reached upon that denotes the number of units that should be crossmatched for that procedure. ${ }^{3}$ The local blood ordering practices and subsequent transfusion of this ordered blood need to be evaluated first. This evaluation serves the primary purpose of assessing the blood ordering practice and provides a basic framework for MSBOS.

We undertook this study to assess the utilization of blood and appropriateness of blood transfusion using utilization indices in a gynecology and obstetrics unit of Abbasi Shaheed Hospital.

\section{Materials and Methods}

For this study, case records of all women who had an elective or emergency procedure in the Department of Obstetrics and

() The Author(s). 20190pen Access This article is distributed under the terms of the Creative Commons Attribution 4.0 International License (https://creativecommons. org/licenses/by-nc/4.0/), which permits unrestricted use, distribution, and non-commercial reproduction in any medium, provided you give appropriate credit to the original author(s) and the source, provide a link to the Creative Commons license, and indicate if changes were made. The Creative Commons Public Domain Dedication waiver (http://creativecommons.org/publicdomain/zero/1.0/) applies to the data made available in this article, unless otherwise stated. 
Gynecology, Abbasi Shaheed Hospital, from July 1, 2016, to December 31, 2016, were compiled and reviewed.

A performa was filled. It included age of the woman, number of units cross-matched for the procedure, and transfused number of patients who had blood cross-matched and transfused. The type of surgery and the type of case were also gathered from the records and entered into the performa.

Data were coded, entered, and analyzed with the help of SPSS version 15 (SPSS Inc., Chicago, IL) for descriptive statistics. Blood utilization indices were calculated as follows:

- Cross-match to transfusion ratio $(C / T$ ratio $)=$ number of units cross-matched/number of units transfused. Appropriate blood utilization is denoted by a ratio of 2.5 or less. ${ }^{11}$

- Transfusion probability (\%T) = number of patients transfused/ number of patients cross-matched $\times 100$. Appropriate blood utilization is denoted a value of $30 \%$ or more. ${ }^{9}$

- Transfusion index (TI) = number of units transfused/number of patients cross-matched. Appropriate blood utilization is denoted a value of 0.5 or more. ${ }^{3}$

- The MSBOS was calculated as 1.5 times of TI.

The main outcome of the study was utilization of blood as determined by the abovementioned parameters.

In lieu of formal ethics committee or formal institutional review board approval, Helsinki's declaration was followed. No subjects were harmed and confidentiality was maintained.

\section{Results}

In the period defined, a total of 598 women had an elective or emergency surgical procedure in the department. These women arranged a total of 1,074 units of blood.

Majority of the women underwent emergency procedures (321, 53.7\%), with cesarean sections $(408,68.2 \%)$ and dilatation and evacuation $(84,14 \%)$ forming the brunt of the cases. The most common indications for the cesarean section were cesarean performed during labor $(146,35.8 \%)$ and cesarean for the previous cesarean section (136, 33.3\%), as shown in Table 1.

From a total of 1,074 units cross-matched, 374 were transfused. Thus, only $34.8 \%$ of the cross-matched blood was utilized. Of the 598 patients for whom blood was cross-matched, only 279 (46.65\%) patients were transfused.

A total of 514 units of blood were cross-matched for women who had an emergency surgery. Only 213 units of these 514 crossmatched units were transfused. Out of these 321 women who had an emergency procedure, 162 received transfusion. A total of 560 units of blood were cross-matched and 143 units were transfused for women who had an elective surgery (Table 2).

The overall blood utilization indices, $\mathrm{C} / \mathrm{T}$ ratio, $\% \mathrm{~T}$, and $\mathrm{TI}$, were $2.87,46 \%$, and 0.62 in the study population (Table 3 ). The values of these indices for elective and emergency cases were different. In elective cases, the $\mathrm{C} / \mathrm{T}$ ratio was 3.9 compared to 2.25 in the emergency cases. The \% $\mathrm{T}$ and $\mathrm{TI}$ for elective cases were $42 \%$ and 0.51 , while those for emergency cases were $50 \%$ and 0.71 .

For cases, the highest C/T ratios were for hysterectomy (7.36), ovarian cystectomy (5.66), and the previous cesarean section (5.66).

The transfusion probability (\%T) was less than $30 \%$ for ovarian cystectomy, the previous cesarean section, and cesareans performed for intrapartum complications.

The TI was less than 0.5 for dilatation and evacuation, hysterectomy, ovarian cystectomy, the previous cesarean section,
Table 1: Case distribution and total units cross-matched and transfused

\begin{tabular}{|c|c|c|}
\hline \multicolumn{2}{|l|}{ Characteristics $(n=598)$} & \multirow{2}{*}{$\begin{array}{l}n(\%) \\
277(46.3\end{array}$} \\
\hline Type of operation & Elective & \\
\hline & Emergency & $321(53.7)$ \\
\hline \multirow[t]{10}{*}{ Cases } & Cesarean & $408(68.2)$ \\
\hline & $\mathrm{D}$ and $\mathrm{E}$ & $84(14.0)$ \\
\hline & Hysterectomy & $32(5.4)$ \\
\hline & Polypectomy & $13(2.2)$ \\
\hline & Myomectomy & $9(1.5)$ \\
\hline & Ovarian cyst & $17(2.8)$ \\
\hline & Ovarian carcinoma suspected & $6(1.0)$ \\
\hline & Tubal surgery & $2(0.3)$ \\
\hline & Others & $15(2.5)$ \\
\hline & Ectopic & $12(2.0)$ \\
\hline \multirow{6}{*}{$\begin{array}{l}\text { Cesarean indications } \\
(n=408)\end{array}$} & APH & $20(4.9)$ \\
\hline & $\mathrm{PIH}$ & $48(11.8)$ \\
\hline & Previous cesarean & $136(33.3)$ \\
\hline & Previa/accreta & $14(3.4)$ \\
\hline & Intrapartum cesarean & $146(35.8)$ \\
\hline & Referred cases & $44(10.8)$ \\
\hline \multicolumn{2}{|c|}{ Total units of blood cross-matched } & 1074 \\
\hline \multicolumn{2}{|c|}{ Total units of blood transfused } & 374 \\
\hline \multicolumn{2}{|c|}{ Total units of blood wasted } & 700 \\
\hline \multicolumn{2}{|c|}{ Total number of patients cross-matched } & 598 \\
\hline \multicolumn{2}{|c|}{ Total number of patients transfused } & 279 \\
\hline
\end{tabular}

Others $=$ procedures not included in the general list mostly performed as a day case

and cesareans performed after the onset of labor due to intrapartum complications (Table 3).

\section{Discussion}

Blood transfusion is quintessential to surgery, where replacing losses is highly desirable. The appropriateness of blood transfusion has been a matter of debate since its inception into medical practice. It is a daunting reality that only $30 \%$ of cross-matched blood for elective surgeries is utilized. ${ }^{11}$

The present study shows underutilization of cross-matched blood in the study setting. Only $38.4 \%$ of the cross-matched units were utilized. The utilization rates reported from India, and Kuwait were $28 \%$ and $69.7 \%$, respectively. ${ }^{2,11}$ The utilization rate varies from $5 \%$ to $40 \%$ worldwide. $^{3}$

The cross-matched to transfusion ratio in our analysis was 2.87, which is higher than the optimum limit. The $\mathrm{C} / \mathrm{T}$ ratio was higher for elective cases than emergency cases (3.9 vs 2.25). This ratio is much higher than the ratio reported by Belayneh et al. ${ }^{12}$ who reported an overall ratio of 2.3 and segregated ratios for elective and emergency cases of 2.9 and 1.8, respectively. A possible reason for this underutilization is the lack of confidence in operating surgeons regarding availability of blood should the need arise. Another common reason cited by senior colleagues is the uncooperative nature of anesthetists. A review showed that the visual estimation of blood loss by anesthetists and gynecologists/obstetricians varies significantly. ${ }^{13}$

The highest $\mathrm{C} / \mathrm{T}$ ratios were for hysterectomy (7.36), ovarian cystectomy (5.66), and the previous cesarean section (5.66). 


\begin{tabular}{|c|c|c|c|c|c|}
\hline & & $\begin{array}{l}\text { No. of units } \\
\text { cross-matched }\end{array}$ & $\begin{array}{l}\text { No. of units } \\
\text { transfused }\end{array}$ & $\begin{array}{l}\text { Patients } \\
\text { transfused n (\%) }\end{array}$ & $\begin{array}{l}\text { Patients cross- } \\
\text { matched n (\%) }\end{array}$ \\
\hline \multirow[t]{2}{*}{ Type of surgery } & Elective & 560 & 143 & $117(41.9)$ & $277(46.3)$ \\
\hline & Emergency & 514 & 231 & $162(58.1)$ & $321(53.7)$ \\
\hline \multirow[t]{10}{*}{ Cases } & Cesarean & 764 & 270 & $197(70.6)$ & $408(68.2)$ \\
\hline & $\mathrm{D}$ and $\mathrm{E}$ & 84 & 32 & $32(11.5)$ & $84(14.0)$ \\
\hline & Hysterectomy & 81 & 11 & $11(3.9)$ & $32(5.4)$ \\
\hline & Polypectomy & 21 & 7 & $7(2.5)$ & $13(2.2)$ \\
\hline & Myomectomy & 36 & 16 & $9(3.2)$ & $9(1.5)$ \\
\hline & Ovarian cystectomy & 17 & 3 & $3(1.1)$ & $17(2.8)$ \\
\hline & Suspected ovarian carcinoma & 14 & 7 & $6(2.2)$ & $6(1.0)$ \\
\hline & Tubal surgery & 2 & 0 & $0(0.0)$ & $2(0.3)$ \\
\hline & Others & 15 & 2 & $2(0.7)$ & $15(2.5)$ \\
\hline & Ectopic & 40 & 26 & $12(4.3)$ & $12(2.0)$ \\
\hline \multirow[t]{6}{*}{ Indication of cesareans } & $\mathrm{APH}$ & 80 & 48 & $20(10.2)$ & $20(4.9)$ \\
\hline & PIH/eclampsia & 96 & 49 & $41(20.8)$ & $48(11.8)$ \\
\hline & Previous cesarean & 272 & 48 & $40(20.3)$ & $136(33.3)$ \\
\hline & Previa accreta & 56 & 28 & $14(7.1)$ & $14(3.4)$ \\
\hline & Intrapartum cesarean & 146 & 39 & 39 (19.8) & $146(35.8)$ \\
\hline & Referred & 114 & 58 & $43(21.8)$ & $44(10.8)$ \\
\hline
\end{tabular}

Table 3: The blood utilization indices

\begin{tabular}{|c|c|c|c|c|c|c|c|}
\hline & $\begin{array}{l}\text { Units cross- } \\
\text { matched }\end{array}$ & $\begin{array}{l}\text { Units } \\
\text { transfused }\end{array}$ & $\begin{array}{l}\text { Patient } \\
\text { transfused }\end{array}$ & $\begin{array}{l}\text { Patient cross- } \\
\text { matched }\end{array}$ & $\begin{array}{l}\text { Index } \\
\left(\mathrm{C} / \text { T ratio }^{*}\right.\end{array}$ & $\begin{array}{l}\text { Transfusion } \\
\text { probability }(\% T)^{*}\end{array}$ & $\begin{array}{l}\text { Transfusion } \\
\text { index }(\mathrm{TI})^{*}\end{array}$ \\
\hline Total & 1,074 & 374 & 279 & 598 & 2.87 & 46 & 0.62 \\
\hline \multicolumn{8}{|l|}{ Type of surgery } \\
\hline Elective & 560 & 143 & 117 & 277 & 3.9 & 42 & 0.51 \\
\hline Emergency & 514 & 231 & 162 & 321 & 2.22 & 50 & 0.71 \\
\hline \multicolumn{8}{|l|}{ Cases } \\
\hline Cesarean & 764 & 270 & 197 & 408 & 2.82 & 48 & 0.66 \\
\hline $\mathrm{D}$ and $\mathrm{E}$ & 84 & 32 & 32 & 84 & 2.65 & 38 & 0.38 \\
\hline Hysterectomy & 81 & 11 & 11 & 32 & 7.36 & 34 & 0.34 \\
\hline Polypectomy & 21 & 7 & 7 & 13 & 3 & 53 & 0.53 \\
\hline Myomectomy & 36 & 16 & 9 & 9 & 2.25 & 100 & 1.77 \\
\hline Ovarian cystectomy & 17 & 3 & 3 & 17 & 5.66 & 17 & 0.17 \\
\hline $\begin{array}{l}\text { Suspected ovarian } \\
\text { carcinoma }\end{array}$ & 14 & 7 & 6 & 6 & 2 & 1 & 1.16 \\
\hline Tubal surgery & 2 & 0 & 0 & 2 & - & 0 & 0 \\
\hline Others & 15 & 2 & 2 & 15 & 7.5 & 13 & 0.13 \\
\hline Ectopic & 40 & 26 & 12 & 12 & 1.53 & 1 & 2.16 \\
\hline \multicolumn{8}{|l|}{ Indication of cesareans } \\
\hline APH & 80 & 48 & 20 & 20 & 1.66 & 1 & 2.4 \\
\hline PIH/eclampsia & 96 & 49 & 41 & 48 & 1.95 & 85 & 1.02 \\
\hline Previous cesarean & 272 & 48 & 40 & 136 & 5.66 & 29 & 0.3 \\
\hline Previa accreta & 56 & 28 & 14 & 14 & 2.0 & 1 & 2 \\
\hline Intrapartum cesarean & 146 & 39 & 39 & 146 & 3.74 & 26 & 0.26 \\
\hline Referred & 114 & 58 & 43 & 44 & 1.96 & 97 & 1.32 \\
\hline
\end{tabular}

*(i) Cross-match to transfusion ratio $(\mathrm{C} / \mathrm{T}$ ratio) $=$ number of units cross-matched/number of units transfused. Appropriate blood utilization is denoted by a ratio of 2.5 or less. (ii) Transfusion probability $(\% \mathrm{~T})=$ number of patients transfused/number of patients cross-matched $\times 100$. Appropriate blood utilization is denoted by a value of $30 \%$ or more. (iii) Transfusion index $(\mathrm{TI})=$ number of units transfused/number of patients cross-matched. Appropriate blood utilization is denoted a value of 0.5 or more. Bold values indicate inappropriate blood utilization 
Injudicious ordering of blood is apparent from these figures for these procedures.

In our study, the transfusion probability was less than $30 \%$ only for ovarian cystectomy, the previous cesarean section, and cesareans performed after the onset of labor due to intrapartum complications, showing an overall appropriate blood ordering in reference to this index. The overall probability was $46 \%$, which is higher than quoted by other studies. ${ }^{14,15}$ The probability was higher for emergency procedures than elective procedures ( $42 \%$ vs $50 \%)$.

The current literature supports that in the absence of significant risk factors, blood type and screen testing for the cesarean section should be eliminated. ${ }^{10}$ A large number of factors affect this decision. ${ }^{16}$

The TI was less than 0.5 for dilatation and evacuation, hysterectomy, ovarian cystectomy, the previous cesarean section, and cesareans performed after the onset of labor due to intrapartum complications. The overall TI was 0.62 , which is similar to that previously reported. ${ }^{2}$

In Pakistan, like other developing countries, the compliance with international guidelines is seldom observed. The doctors are not used to following any standard criteria. They base their decisions to order blood on several parameters such as past experience, personal judgment, and prescribing by habit. ${ }^{7}$

In our study, all cases had their blood cross-matched. The hospital blood bank's policy is to ensure that a donor pays and bleeds before blood is reserved for the patient. In case blood is not utilized by the patient but has not been cross-matched, the money is refunded. In most cases, the group and save strategy can prove efficient and reduce the burden of arranging blood. ${ }^{17}$

Another aspect that needs discussion is the fact that the distance from the blood bank to the operating room is a significant restricting parameter when proposing a group and save strategy. But this can be overcome with good counseling and optimum transport facilities. The blood ordering practices need to be reviewed from time to time and a MSBOS devised for efficient use of resources. Further studies need to be undertaken to evaluate the effect of its implementation in the set-up.

\section{CONCLUSION}

Our study showed underutilization of blood in terms of crossmatched to transfusion ratio but the probability of transfusion and TI was appropriate. A blood ordering policy needs to be formulated and implemented in the set-up to ensure appropriate utilization of blood.

\section{Ethical Approval}

In lieu of formal ethics committee or formal institutional review board approval, Helsinki's declaration was followed. No subjects were harmed and confidentiality was maintained.

\section{References}

1. Hall TC, Pattenden C, Hollobone $C$, et al. Blood transfusion policies in elective general surgery: how to optimise cross-match-totransfusion ratios. Transfus Med Hemother 2013;40(1):27-31. DOI: 10.1159/000345660.

2. Vibhute M, Kamath SK, Shetty A. Blood utilization in elective general surgery cases: requirements, ordering and transfusion practices. J Postgrad Med 2000;46(1):13-17.

3. Friedman BA, Oberman HA, Chadwick AR, et al. The maximum surgical blood order schedule and surgical blood use in the United States. Transfusion 1976;16(4):380-387. DOI: 10.1046/j.15372995.1976.16476247063.x.

4. Singh JK, Singh P. Routine pre-operative cross-match for elective colorectal resections: an appropriate use of resources? Surgeon 2011;9(1):8-12. DOI: 10.1016/j.surge.2010.06.008.

5. Ma M, Eckert K, Ralley F, et al. A retrospective study evaluating single-unit red blood cell transfusions in reducing allogeneic blood exposure. Transfusion Med 2005;15(4):307-312. DOI: 10.1111/j.09587578.2005.00592.x.

6. Afzal S. A comparison of public and private hospital on rational use of blood in Islamabad. J Pak Med Assoc 2013;63(1):85-89.

7. World Health Organization. Universal access to safe blood transfusion. Available from URL: http://www.who.int/bloodsafety/publications/ UniversalAccesstoSafeBT.pdf.

8. Boral LI, Henry JB. The type and screen: a safe alternative and supplement in selected surgical procedures. Transfusion 1977;17(2):163-168. DOI: 10.1046/j.1537-2995.1977.17277151923.x.

9. Mead JH, Anthony CD, Sattler M. Hemotherapy in elective surgery: an incidence report, review of the literature, and alternatives for guideline appraisal. Am J Clin Pathol 1980;74(2):223-227. DOI: 10.1093/ ajcp/74.2.223.

10. Olawumi HO, Bolaji BO. Blood utilization in elective surgical procedures in Ilorin. Trop J Health Sci 2006;13(1):15-17. DOI: 10.4314/ tjhc.v13i1.36702.

11. Sowayan SA. Use of blood in elective surgery: an area of wasted hospital resource. Ann Saudi Med 1994;14(4):326-328. DOI: 10.5144/0256-4947.1994.326.

12. Belayneh T, Messele G, Abdissa Z, et al. Blood requisition and utilization practice in surgical patients at University of Gondar Hospital, Northwest Ethiopia. J Blood Transfus 2013;2013:758910. DOI: $10.1155 / 2013 / 758910$.

13. Khan FA, Khan M, Ali A, et al. Estimation of blood loss during Caesarean section: an audit. J Pak Med Assoc 2006;56(12):572-575.

14. Yazdi AP, Alipour M, Jahanbakhsh SS, et al. A survey of blood request versus blood utilization at a university hospital in Iran. Arch Bone Jt Surg 2016;4(1):75-79.

15. Ibrahim SZ, Mamdouh HM, Ramadan AM. Blood utilization for elective surgeries at main university hospital in Alexandria, Egypt. J Am Sci 2011;7(6):683-689.

16. Goundan A, Kalra JK, Raveendran A, et al. Descriptive study of blood transfusion practices in women undergoing cesarean delivery. J Obstet Gynaecol Res 2011;37(10):1277-1278. DOI: 10.1111/j.14470756.2010.01511.x.

17. Begic D, Mujicic E, Coric J, et al. The management of transfusion services, analysis and assessment. Mater Sociomed 2016;28(4): 274-277. DOI: 10.5455/msm.2016.28.274-277. 